\title{
Common Respiratory Fungal Pathogens in Municipal Solid Waste Workers in Anambra State, Nigeria
}

\author{
I.M. Ekejindu ${ }^{1}$, C.F. Aniebue ${ }^{1}$, M.T.B. Ochiabuto ${ }^{1}$ and E.I. Obeagu ${ }^{2 *}$ \\ ${ }^{1}$ Department of Medical Laboratory Science, Nnamdi Azikiwe University, Nnewi Campus, \\ Nnewi, Anambra State, Nigeria \\ ${ }^{2}$ Department of Health Services, Michael Okpara University of Agriculture, Umudike, \\ Abia State, Nigeria \\ *Corresponding author
}

\section{A B S T R A C T}

A study on common respiratory fungal pathogens in municipal solid waste workers was done in Anambra State, Nigeria. A total of 53 symptomatic and asymptomatic workers of age bracket $20-50$ years and above, were recruited with 32 non-solid waste workers used as control. Demographical data was obtained using questionnaire. Fungal isolation from sputum was done using standard cultural methods. Haematological indices were done using standard staining and microscopic methods respectively. Identification of isolates

\section{Keywords}

Respiratory, Fungal pathogens,

Municipal, Solid-

Waste workers.

\section{Article Info}

Accepted: 07 September 2017 Available Online: 10 October 2017 was carried out using Slide-culture technique and germ-tube tests. Results obtained showed that a total of 30 workers had different fungal isolates $(56.6 \%)$ in their sputum culture, while 23 (43.4\%) had no isolates. There was no significant difference $(\mathrm{P}>0.05)$ between those with isolates and those without a positive isolates. Different isolates obtained include, Aspergillus flavus 5(6.3\%), A. niger 16 (20.0\%), Candida albicans 8 (10.0\%), C. herbarum 8 (10.0\%), Trichoderma viride $5(6.3 \%)$, Penicillium marneffei 6 (7.5\%), A. fumigatus $9(11.3 \%)$ and no growth $23(28.8 \%)$. There was no correlation between the prevalence of respiratory fungal infection on the age and sex of the solidwaste workers $(\mathrm{p}>0.05)$. In the study, $6(11.3 \%)$ of the workers had only one fungal isolate, $18(24 \%)$ had 2, while $6(11.3 \%)$ had 3 fungal isolates in each sputum sampled. Increased length of work exposure had a profound effect on the number of fungal isolates obtained. Cough was the highest chronic symptom associated with the work. Hematological indices shows a statistical difference between mean values of total white cell count (p. value 0.000), Neutrophil count (P- value 0.040) and eosinophil count (p. value 0.000$)$ in the case subjects and control groups $(\mathrm{p}<0.05)$. No significant difference exists in the mean values of PCV, lymphocyte count and monocyte count of the case subjects and control. Conclusively, the research shows that the incidence of fungal infection is related to the number of years in the job, work habits and also had a significant effect on the hematological parameters such as Total WBC, eosinophils and neutrophil.

\section{Introduction}

Municipal solid-waste is total waste which excludes industrial waste, agricultural waste, and sewage sludge. It includes durable goods, non-durable goods, containers and packaging, food waste, yard wastes, and miscellaneous inorganic wastes from residential, commercial, and institutional sources (EPA, 2012). Examples from these categories 
include appliances, newspapers, and clothing. Solid waste handling and disposal is a growing environmental and public health concern. The collection of household waste is a very hard job, which entails working in a vehicle that moves through traffic throughout the year. It also requires heavy physical activities, such as manual lifting and handling of heavy bins.

Municipal solid-waste workers (MSWWs) are exposed to a number of pathogens (bacteria, fungi, viruses and parasites), toxic substances (Endotoxins and beta glucans), chemicals that come from the waste itself and its decomposition, as well as vehicle exhaust fumes, noise, extreme temperatures and ultraviolet radiation (Lavoie et al., 2006).

As a result of their exposure to multiple risk factors, municipal solid waste workers suffer high risk of occupational health problems (Dorevitch and Marder, 2001).

Aerosols generated by decaying organic waste, exhaust fumes and bad weather conditions may all contribute to respiratory problems (Hansen, 1997).

Bioaerosols are particulate matter of microbial, plant or animal origin that is often used synonymously with organic dust.

The interest in bioaerosol exposure has increased over the last few decades. This is largely because it is now appropriately recognised that exposures to biological agents in both occupational and residential indoor environment are associated with a wide range of adverse health effects with major public health impact, including contagious infectious diseases, acute toxic effects, allergies and cancer (Douwes et al., 2000).

Bioaerosols contain several agents capable of inducing inflammation in the airways and a typical pneumonia. Endotoxins and fungal spores are regarded as the most potent inflammatory components in bioaerosols (Heldal, 2003). There is increasing evidence that diseases caused by exposure to bioaerosols are mainly of non-allergic inflammatory nature. Bioaerosol exposure is also associated with health effects such as respiratory symptoms, influenza - like symptoms and increased risk of chronic obstructive pulmonary disease (COPD) (Matheson, 2005). There is limited information on exposure levels of bioaerosols during waste collection (Heldal, 2004). However, it has been shown that moderate inhalation or exposure to fungal spores and beta glucans, and even low exposure to endotoxins during waste handling, induce upper airway inflammation characterized by neutrophil influx and activation (myeloperoxidase, eosinophil cationic protein and interleukins) (Heldal, 2003).

The incidence of work related pulmonary problems seems to be greater in waste collectors than in general workforce. This occupation is physically strenuous, resulting in workers breathing through their nose (Cointreau-Levine et al., 1998).

Some of the respiratory fungal) pathogens of interest to be isolated include those of Aspergillus spp. Penicillium spp., Candida spp. Alternaria spp., Cladosporium spp., Trichoderma spp. etc.

Currently much report on upper air-way inflammation due to bioaerosol inhalation by solid waste workers have not been done in South Eastern Nigeria and Anambra state precisely.

The main objectives of this study, to determine the prevalence of common respiratory (fungal) infections in municipal solid - waste workers. To determine the 
genus and species of the fungal agent associated with the respiratory infection. And to determine the effect of gender and age on the prevalence of respiratory (fungal) infections. The effect of different lengths of exposure at work on the number of fungal isolates was established. Also, to determine and compare the effects waste working on hematological indices of municipal solid waste workers with those of the general public (non - solid waste workers).

\section{Materials and Methods}

\section{Research design}

This study is purely an occupational cohort study, designed to assess the prevalence of common respiratory fungal pathogens and hematological findings in municipal solidwaste workers and also scavengers in the major cities in Anambra state which includes; Awka, Onitsha, and Nnewi.

These set of individuals seem to be more exposed to the agent (bioearosols).

\section{Area of Study}

This research was carried out in 3 major cities in Anambra state which include; Awka, Onitsha, and Nnewi.

Awka is the capital of Anambra state, Nigeria with an estimated population of 301, 657 (FRNOG, 2006) as of 2006 Nigerian census.

The city is located about 600 miles east of Lagos in the centre of the densely - populated Igbo health and in Southeastern Nigeria.

The west - east federal highway links Lagos, Benin city, Asaba, Onitsha, and Enugu to Akwa and several local roads link it to other important towns such as Ekwulobia, Agulu, Enugwu - ukwu, Abagana and Nnewi (Egbokhare et al., 2002).
Strategically, Awka is located midway between two major cities in Northern Igboland, Onitsha and Enugu which has informed its choice as an administrative center for the colonial authorities and today as a base for the Anambra state government.

Awka comprises seven Igbo groups sharing common blood lineage divided into two sections. Ifite section, the senior section, comprises 4 groups Ayom - na - Okpala, Nkwelle, Amachalla and Ifite - Oka followed by Ezinator section, which consists of three groups, Amikwo, Ezi-oka and Agulu.

Awka should not be confused with AwkaEtiti. This is a town in Idemili South local government area that is often mistaken for the main capital (Britannica concise Encyclopedia, 2007). Today it is the capital of Anambra state of Nigeria. Slogan: sires.

\section{Onitsha}

Onitsha is a city, a commercial, educational, and religious centre and river port on the eastern bank of the Niger River in Anambra state, southeastern Nigeria (Okanga et al., 2003).

In the early 1960's before the Nigerian civil war, the population was officially recorded as 76,000 , and the town was distinctive in a number of dimensions by 2001, its population has been placed at 511,000 with a metropolitan population of $1,003,000$ (Minahan, 2002) it is currently one of the fastest growing cities in the World. Onitsha is majorly dominated by Igbos.

\section{Nnewi}

Nnewi is the second largest city in Anambra state in Southeastern Nigeria. Nnewi as a metropolitan city encompasses two local government areas, Nnewi North and Nnewi 
South; Nnewi North is commonly referred to as Nnewicentral and comprises four autonomous quarters: Otolo, Uruagu, Umudim, and Nnewichi. Nnewi North also includes Ichi, an autonomous neigbouring town.

As of 2006, Nnewi has an estimated population of 391,227 according to the Nigerian census. The city spans over $1,076.9$ square rules $\left(2,789 \mathrm{~km}^{2}\right)$ in Anambra State. Nnewi Metropolitan Area and its satellite towns is a home to nearly 2. 5 million residents as of 2005. Dimensionally, Nnewi has an edge over all other units, being recognized by the 1953 figures as the largest inland town in the Eastern States.

\section{Ethical consideration}

Ethical approval for this research was obtained from Nnamdi Azikiwe University Teaching Hospital Ethical Committee.

Informed consent was sought from each of the evacuators by group interaction. Confidentiality was maintained in accordance with the ethics of Medical Laboratory Science Practice of Nigeria.

\section{Research population}

The population used in the study were Municipal solid - waste workers, working under Anambra State Waste Management Authority (ASWAMA) $(\mathrm{n}=37)$.

Scavengers doing hand picking of materials at the dump - site at Onitsha-Owerri road) $(\mathrm{n}=$ 16).

Control samples from non - solid waste workers from the same age range $(n=32)$.

\section{Sample size and sampling techniques}

A sample size of 53 workers, with at least one year of active duty, within the age bracket of
(20 - 50yrs and above), who gave their consent to participate in the study were recruited from the above named company. Also 32 subjects were equally selected from non - solid waste workers, whose age bracket matches those of the workers. 10 subjects were both selected from Onitsha and Awka while 12 subjects were picked from Nnewi.

\section{Method of data collection}

\section{Issuance of a questionnaire}

Questionnaire was given to the subjects in order to obtain relevant information such as;

Demographic data which includes sex, age, marital status and how long he/she has been in the job.

Questions on assessment of lifestyle which includes; smoking habits, wearing of face mask, wearing of protective hand gloves while on duty etc.

Also on assessment of work associated symptoms like sore throat, itchy skin, irritation of the eyes, headache, cough, wheezing etc.

Questions were also asked on assessment of attitude. The questionnaire is attached in appendix I below.

\section{Specimen collection and preparation}

Prior to specimen collection, awareness was created by group interactions and questionnaire was issued to the participants following outlined guidelines on how to fill the questionnaire.

\section{Blood}

According to the method described by Cheesbrough (2005), $5 \mathrm{mls}$ of blood specimen were collected through venepuncture from the 
participant and dispensed into an appropriately labeled EDTA container for estimation of their full blood count (FBC), which includes pcv, total white cell count and differential white count.

\section{Sputum}

A clean, dry, wide - necked, leak - proof container was given to the subjects, requiring them to cough deeply to produce a sputum specimen.

The need for saliva not to be introduced into the specimen was clearly stressed. The containers wee appropriately labeled kept for sputum culture on Saboraud dextrose agar (SDA) in the laboratory.

\section{Sputum culture}

Each labelled sample was cultured on 3 plates, one with only saboraud agar (s),the second plate contains saboraud agar with antibiotics (chloramphenicol) and the $3^{\text {rd }}$ plate containedsaboraud, antibiotics, and antifungal agent (cycloheximide). They were incubated at room temperature for a period of $3-4$ days. Methods used were as described in Cheesbrough (2005).

\section{Plate reading}

This was done visually according to guidelines described by Ochei and Kolhatkar (2000) noting the colour, texture, topography, diffusible pigments and reverse of the isolates.

\section{Identification of isolates}

The microscopic morphological features of most fungi are stable and exhibit minimal variations. Definitive identification is based on the morphology of the spores and hyphae, this was done using lactophenol cotton blue stain according to methods described in
Cheesbrough (2005) and viewed at x10 and $\mathrm{x} 40$ objective. Based on the morphology of the colonies identified, the isolates were placed on their genera and species using the methods described in (Dehoog et al., 2000).

\section{Identification of Candida species}

Germ -tube test was used for identification of Candida species according to methods described in Ochei (2000). Control used was a known culture of Candida albicans (positive control)

\section{Full blood count (Manual method)}

Packed cell volume (PCV) using micro haematocrit method

\section{Thin blood film preparation}

\section{Procedure}

A small drop of blood was placed at one end of a clean, grease - free slide.

A glass spreader was placed in front and in contact with the blood at an angle of about $45^{\circ}$, the blood was allowed to spread along the line of contact.

The blood was spread along the length of the slide in a swift and steady movement making sure that the film has a head, body and tail. The slide is labeled with the participant number and allowed to air dry, taking care to avoid dust and insects perching on the film.

\section{Staining of thin blood film}

\section{Procedure for staining}

The thin film was covered with undiluted Leishmann stain to fix for 2 mins (The methanol in the Leishmann fixes the white cells while Leishmann stains the cell). It was differentiated with buffered distilled water of 
$\mathrm{Ph} 6.8$, for 8 mins (twice the volume of the stain).

The stain was washed off with tap water. The stain was not tipped off in order to avoid leaving a fine deposit covering the film.

The back of the slide was wiped clean and placed on the draining rack for the smear to dry.

The film was viewed microscopically with $\mathrm{x}$ 100 objectives using oil immersion.

The counts were made using manual counter.

\section{Total white cell count}

1 in 20 dilution of the blood was done by adding $0.38 \mathrm{ml}$ of Turk's solution to $0.02 \mathrm{ml}$ of the EDTA - anticoagulated blood

The mixture was allowed for 5minutes, so that the nucleated cells become sufficiently stained.

The improved Neubauer counting chamber was charge properly by placing a cover slip firmly over the counting area, making sure that the newton rings are seen.

The diluted blood sample was mixed adequately and a capillary tube was used to collect a small amount into the charged chamber.

The cells in the larger outer squares are counted microscopically using $10 \mathrm{x}$ objectives. The number of cells counted was divided and reported as number of cells x $10^{9}$ per litre of blood.

\section{Results and Discussion}

Table 1 shows that $30(56.6 \%)$ of the municipal solid - waste workers had one or more of the respiratory fungi, which may cause respiratory fungal infection, while $23(43.4 \%)$ had no growth.

The chi square statistical analysis shows that the result is insignificant, since the p-value is greater than $0.05(\mathrm{p}=0.336)$ and therefore $(\mathrm{P}>$ 0.05). This entails in essence that null hypothesis holds on it.

Table 2 is a frequency and percentage table of the common fungal agent isolated from the waste workers.

The result shows that Aspergillus flavus was isolated from $5(6.3 \%)$ of the subjects, Aspergillus niger was isolated from $16(20.0 \%)$ subjects, Candida albicans were isolated from $8(10.0 \%)$ workers, Cladosporium herbarum was isolated from $8(10.0 \%)$ subjects, Trichoderma viride was isolated from $5(6.3 \%)$ of the subjects, Penicillium marneffei was isolated from $6(7.5 \%)$ of the workers, while Aspergillus fumigatus was isolated from $9(11.3 \%)$ of the workers and about 23(28.8\%) of the workers had no growth. With (chi-square) $\mathrm{X}^{2}=28.000$ and $\mathrm{P}$-value $=0.000$, since it is less than 0.05 i.e. $(\mathrm{P}<0.05)$, the result is statistically significant.

Table 3 shows the correlation between sex and age on the prevalence of respiratory fungal infection in Municipal solid -waste workers. The result shows that there is no statistically established correlation between age and sex on the prevalence of respiratory fungal infection since the $p$-value is $(p>0.05)$.

From figure 1 above, the results obtained shows that $6(11.3 \%)$ of the workers had only one fungal isolate, $18(34 \%)$ of the workers had two fungal isolates, while $6(11.3 \%)$ of the workers had three fungal isolates growing. $23(43.4 \%)$ had no growth. 
Figure 2 is a multiple component bar chart showing the different years of work exposure, as they affect the number of fungal agents isolated.

From figure 2 workers having work experience/exposure of 1-2 years were highest in frequency and they are 24(45.3\%) of the workers; of this workers, 2 had only one fungal agent, while 10 workers had 2 fungal isolates, 2 workers had 3 isolates growing, while 10 workers had no growth.

On the other hand, $11(20.8 \%)$ of the workers have 3-4 years of experience, with which 3 has one fungal isolate, none of the workers had 3 isolates, while 2 had no growth (Fig. 3 ).

Also workers within the work exposure rang of 5-6 years were totaling 12 in number $(n=12)$, out of this, none had one fungal growth, while 5 had 2 fungal agents growing and 4 of the workers had 3 different isolates, while 3 out of 12 of the workers had no fungal growth.

Those with 7 and above years of exposure were 6 in total, 4 workers had 3 different fungal isolates growing on the same plate, 2 of the workers had no growth, while none of the workers neither showed one or two growths of fungal isolates.

Table 4 shows the mean, standard deviation and t-test comparison of the various hematological parameters in case (solid-waste workers) and control groups (Non-solid waste workers), The results obtained showed that there were statistically established difference between the mean values of total white cell count (T.wbc) (P. value 0.000), neutrophil count (P. value 0.040), eosinophil count (P. value 0.000$)$, in both the case/subjects and the control groups. i.e. $(\mathrm{P}<0.05)$ and therefore statistically significant. They are denoted by one asterisk (*). Results obtained equally shows that there were no statistically established difference between the mean values of PCV, lymphocyte count, monocyte count in both subjects and control hence (p.> 0.05 ) and so not significant.

Table 5 shows that red blood cells and platelets morphology in both the subject and control groups were completely normal.

The result shows that $8(15.1 \%)$ of the respondents has cultivated the habit of smoking always, 6(11.3\%) of the workers smoke sometimes, $4(7.5 \%)$ of the workers rarely smoke, while $35(66 \%)$ never smokes.

Two $(3.2 \%)$ out of the total population wear facemask always, while $7(13.2 \%)$ workers wear it sometimes, $4(7.5 \%)$ rarely wears facemask, 40(75.4) of the workers never wear facemask. Five $(9.4 \%)$ of the workers always wear protective clothings, $8(15.1 \%)$ wear protective clothing sometimes, while $3(5.7 \%)$ rarely wear protective clothings and $37(70 \%)$ of the respondent do not wear protective clothings. Four $(7.5 \%)$ out of the whole workers wear protective hand gloves always, $3(5.7 \%)$ wear it sometimes, none do it rarely, while $46(87 \%)$ of the workers never wear protective hand gloves (Fig. 4).

The result above shows that $35(66.0 \%)$ of the total number $(\mathrm{N}=53)$, experienced major chronic symptoms such as cough, 28 (52.8\%) of the workers experienced phlegm production, $22(41.5 \%)$ have wheezing, 19 $(35,8 \%)$ complained of other major symptoms such as dyspnea (i.e.) shortness of breather, while $13(24.5 \%)$ complained of other major symptoms such as fatigue and low waist pain, this particularly due to the nature of the materials (sludge) they carry manually (Fig. $5)$.

Municipal solid-waste workers are exposed to bioaerosols collecting household and commercial wastes, the incidence of work related pulmonary, gastrointestinal and skin 
problems may be greater in waste collectors than in the general work force. Knowledge of the aetiology of these problems is limited, but it is likely that they are caused by exposure to bioaerosols or volatile organic compounds. Studies in other occupational environment with high exposure to bioaerosols may cause a wide range of respiratory and mucosal symptoms that membrane limitations to acute and chronic disease such as toxic alveolitis (also known as organic dust toxic syndrome, ODTS), allergic alveolitis and asthma (Lacey and Dutkiewicz, 1994) (Fig. 6).

\begin{tabular}{|c|c|c|}
\hline & GROUP & VILLAGE \\
\hline & Ayom $-\mathrm{Na}$ & $\begin{array}{l}\text { Umuayom, umunnoke, Okpala Umuoramma and } \\
\text { Umokpu }\end{array}$ \\
\hline 2 & Nkwelle & Achallaoji, Umunamoke, Umudiaba \\
\hline & Amachalla & Amachalla, Amudo, Umuzocha \\
\hline & Ifite - oka & $\begin{array}{l}\text { Enu - ifite, Ezinato - IfitAgbana } \\
\text { Ifite }\end{array}$ \\
\hline & Amikwo & $\begin{array}{l}\text { Umudiana, okperi, Igweogige, } \\
\text { Isiagu, Obunagu }\end{array}$ \\
\hline 6 & Ezi - oka & $\begin{array}{l}\text { Omuko, Umueri, Umuogwal, } \\
\text { Umuogbunu1, Umuogbunu 2, umudioka, Umukwa. }\end{array}$ \\
\hline & Agulu & $\begin{array}{l}\text { Umuogbu, Umubele, } \\
\text { Umuanega Umuike, Umujagwo, Umuenechi, } \\
\text { umuoruka. }\end{array}$ \\
\hline
\end{tabular}

Table.1 This table shows the frequency distribution of the prevalence of fungal respiratory infections in the municipal solid-waste workers (MSWWS)

\begin{tabular}{l|l|l} 
& FREQUENCY & PERCENTAGE $(\%)$ \\
\hline FUNGAL ISOLATES & 30 & 56.6 \\
NO GROWTH & 23 & 43.4 \\
TOTAL & 53 & 100.0 \\
\hline & $\mathrm{X}^{2}=0.925$, & $\mathrm{P}=0.336(\mathrm{P}>0.05)$
\end{tabular}

Table.2 Shows the frequency distribution and percentages of the fungal isolate from the municipal solid -waste workers

\begin{tabular}{l|l|c} 
Fungal Isolate & Frequency & Percentage \\
\hline Aspergillus flavus & 5 & 6.3 \\
Aspergillus niger & 16 & 20.0 \\
Candida albicans & 8 & 10.0 \\
Cladosporium herbarum & 8 & 10.0 \\
Trichoderma viride & 5 & 6.3 \\
Penicillium marneffei & 6 & 7.5 \\
Aspergillus fumigatus & 9 & 11.3 \\
No Growth & 23 & 28.8 \\
\hline & $\mathrm{X}^{2}=28.000$, & $\mathrm{P}=0.00$
\end{tabular}


Table.3 Shows the correlation between sex and age on the prevalence of respiratory fungal infection in Municipal solid-waste workers (MSWWS)

\begin{tabular}{l|lll} 
& $\mathrm{R}=$ (correlation coefficient) & $\mathrm{P}-$ Yalue & \\
\hline Prevalence Vs Sex & 0.155 & 0.268 & \\
Prevalence Vs Age & -0.030 & 0.832 & P>0.05 (Not significant)
\end{tabular}

Table.4 Hematological parameters of solid waste workers and non- solid waste workers

\begin{tabular}{|l|l|l|l|l|l|l|}
\hline PARAMETER & GROUPS & $\mathrm{N}$ & MEAN & STD. DEVIATION & T & P-Value \\
\hline PCV & case subject & 53 & .3902 & .04181 & & $* *$ \\
& control group & 32 & .39 & .3250 & -0.991 & 0.325 \\
\hline \multirow{2}{*}{ T.WBC } & Case subject & 53 & 6.992 & 2.2974 & & $*$ \\
& Control group & 32 & 8.950 & 2.5147 & 3.673 & 0.000 \\
\hline \multirow{2}{*}{ NEUT. } & Case subject & 53 & 40.38 & 9.853 & & $*$ \\
& Control group & 32 & 45.56 & 12.894 & 2.089 & 0.040 \\
\hline \multirow{2}{*}{ BASO } & Case subject & - & - & - & - & - \\
& Control group & - & - & - & - & - \\
\hline \multirow{2}{*}{ EOSIN. } & Case subject & 53 & 5.47 & 3.544 & & $*$ \\
& Control group & 18 & 2.72 & 2.137 & 3.925 & 0.000 \\
\hline \multirow{2}{*}{ LYMPHO. } & Case subject & 53 & 52.70 & 11.991 & -0.109 & $* .913$ \\
\hline \multirow{2}{*}{ MONO } & Control group & 32 & 53.00 & 12.894 & & $* *$ \\
& Case subject & 7 & 7.14 & 15.816 & 1.028 & 0.344 \\
\hline
\end{tabular}

KEY: $*$ Significant, $* *=$ Not Significant

Table.5 Shows the morphology distribution and percentage of the normal and abnormal red cells and platelets

\begin{tabular}{l|l|l|l|l} 
& & CASE & & CONTROL \\
\hline MORPHOLOGY & $\mathrm{N}$ & PERCENTAGE (\%) & $\mathrm{N}$ & PERCENTAGE (\%) \\
Normal RBC & 53 & 100 & 32 & 100 \\
Abnormal RBC & 0 & 0 & 0 & 0 \\
Normal Platelets & 53 & 100 & 32 & 100 \\
Abnormal Platelets & 0 & 0 & 0 & 0 \\
\hline
\end{tabular}


Fig.1 Shows a bar chart of the number of workers with none, one or more fungal isolates

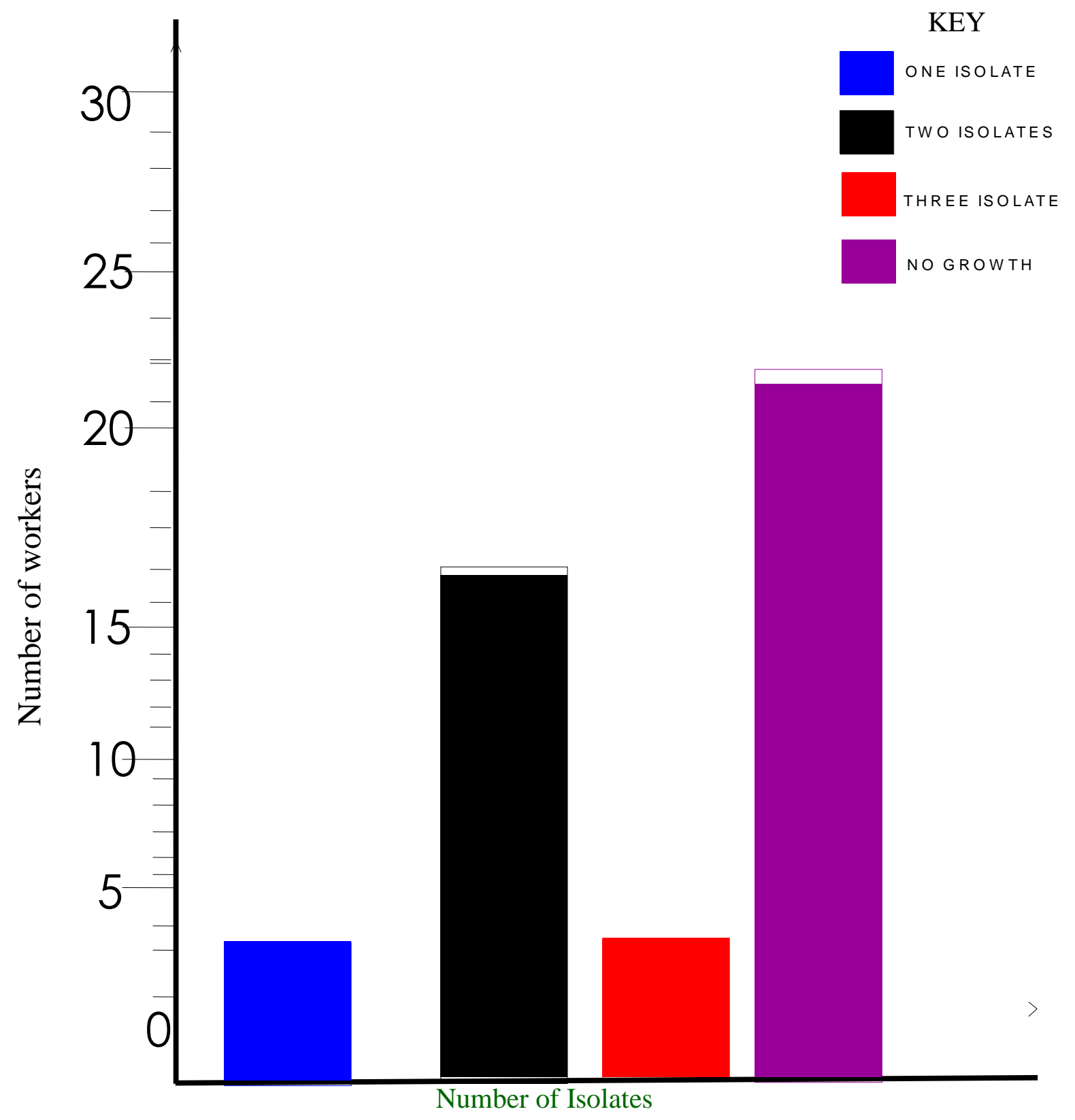


Fig.2 This Bar chart represents the different rates of work exposures and their effects on the incidence of respiratory infection

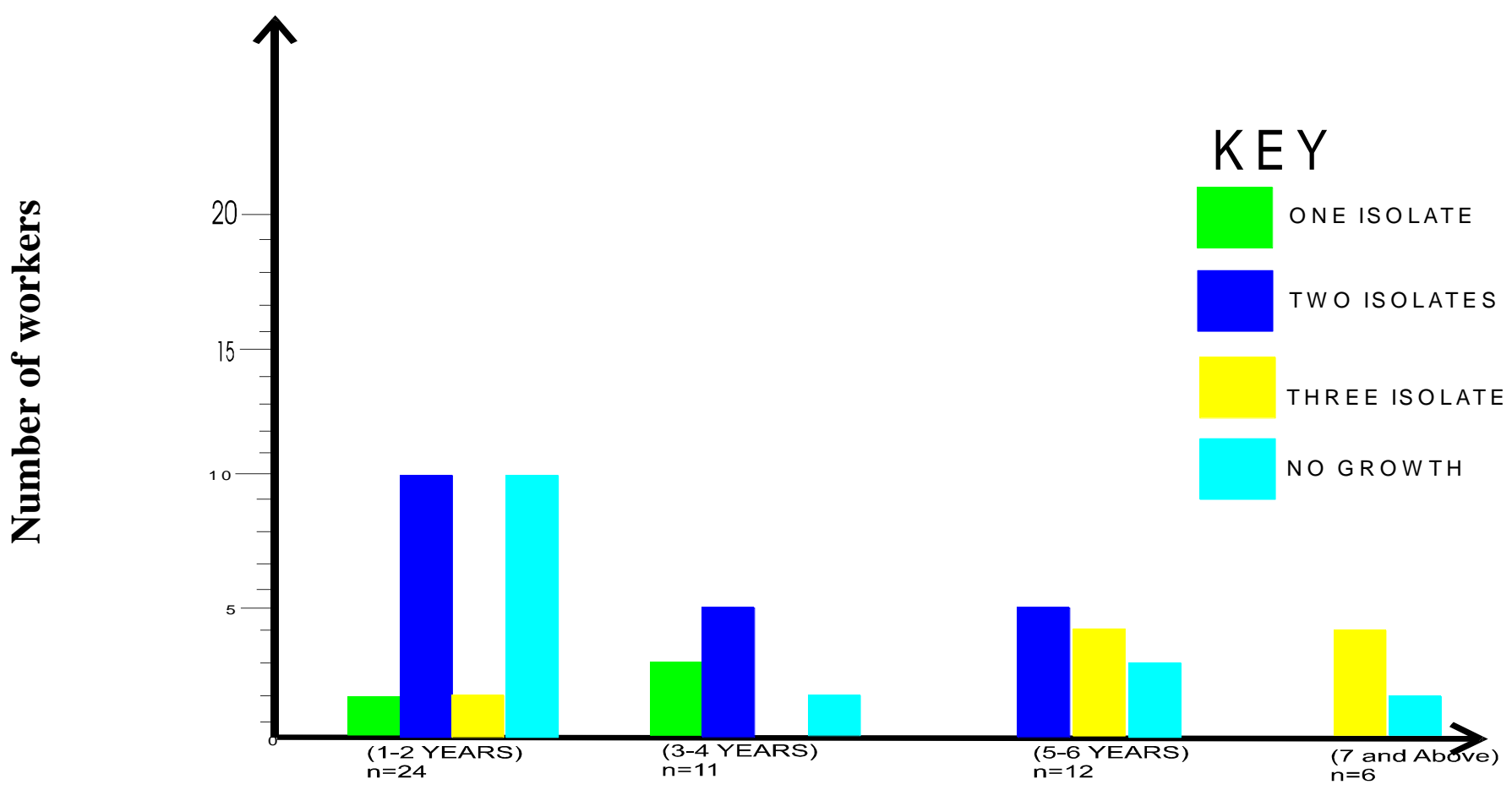

Fig.3 Length of time worker, have been on the job

Question 3: How long have you been in the job?

$(\mathrm{N}=$ Total Number of workers $=53$ )
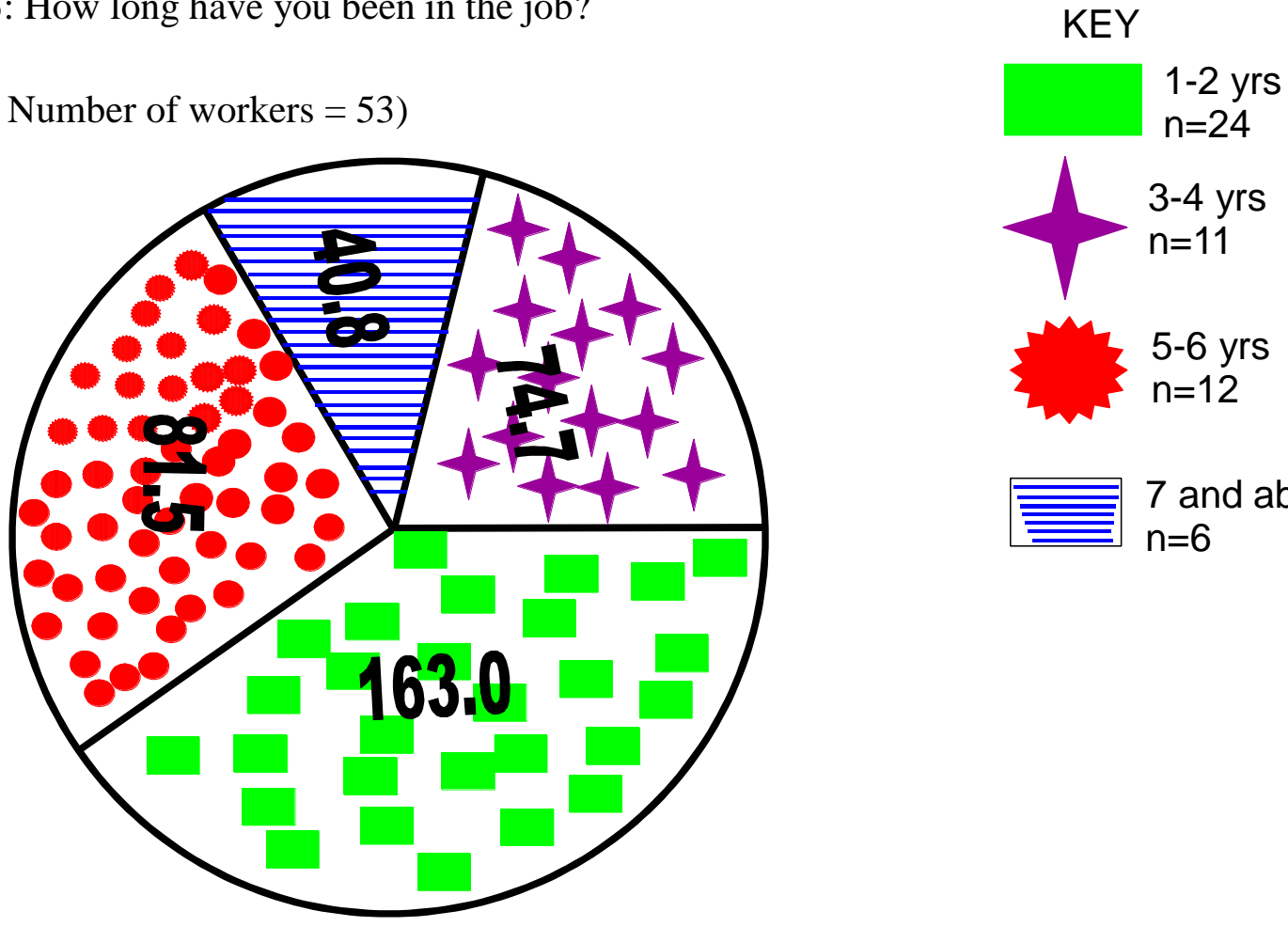
Fig.4 Life style of workers

\section{KEY}

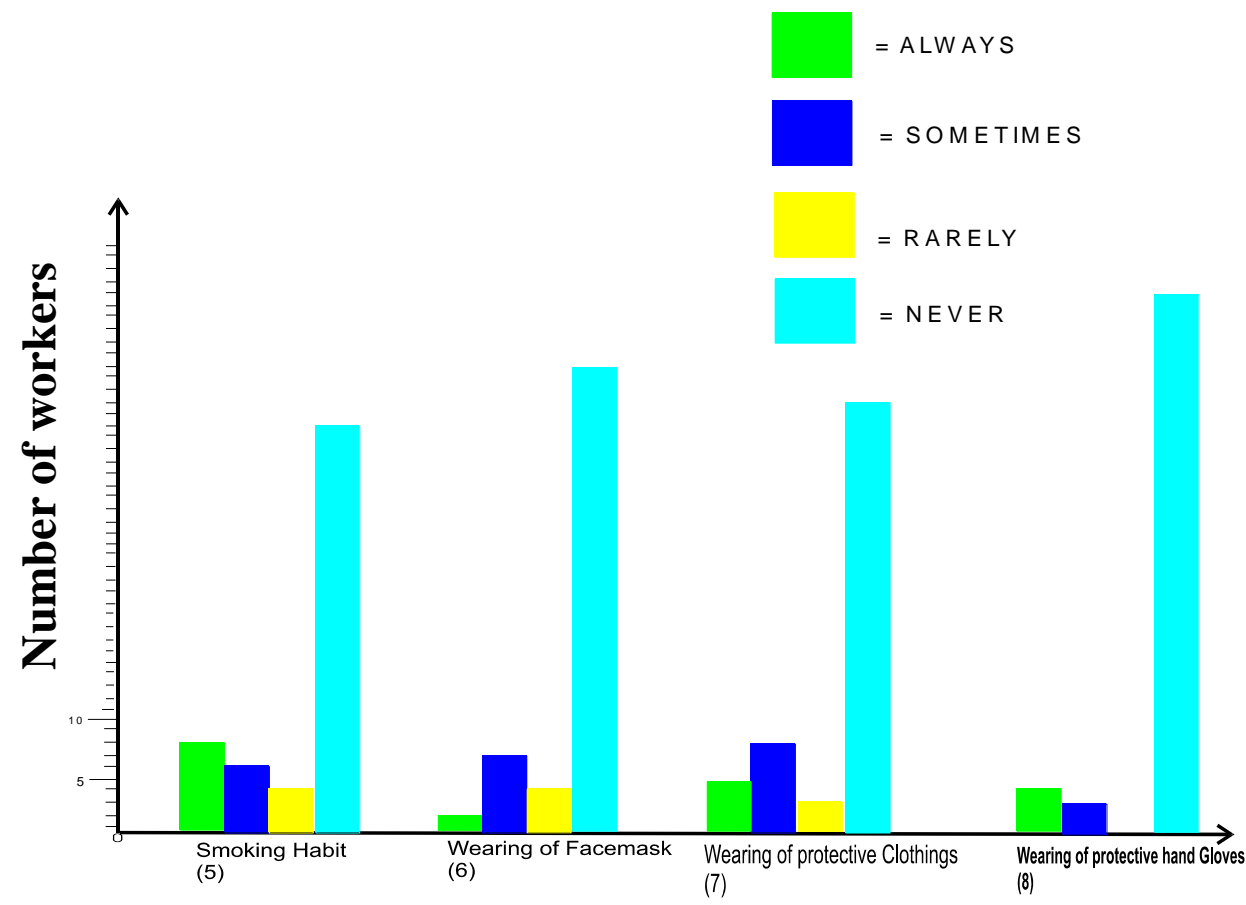

Fig.5 Distribution of work associated respiratory symptoms

QUESTION 10:- How many of these symptoms have you experienced in the past one month? (Acute symptoms)
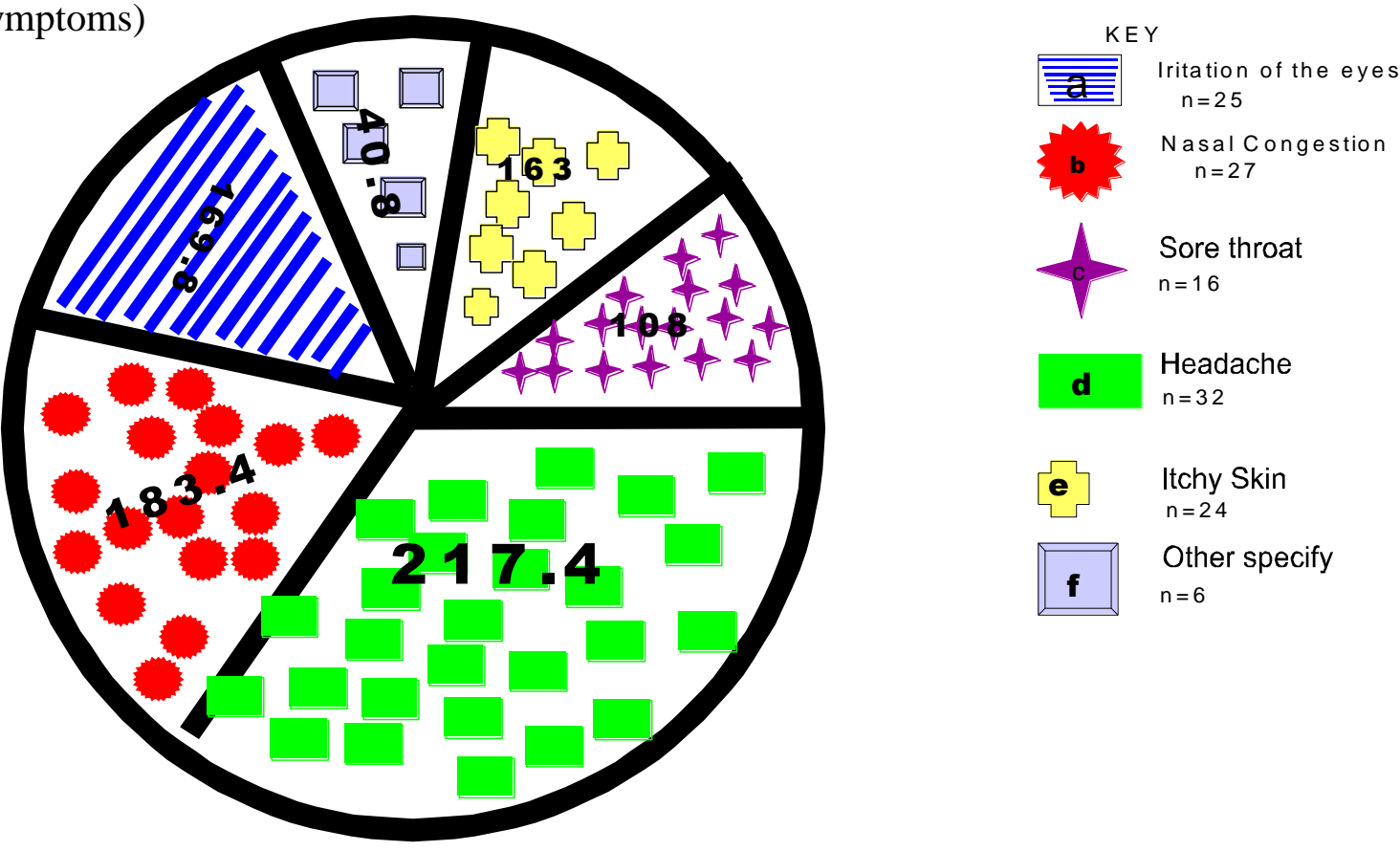
Fig.6 Chronic symptoms of respiratory infections in solid-waste workers

QUESTION 11:- How many of these symptoms have you been experienced for the past 2 years:
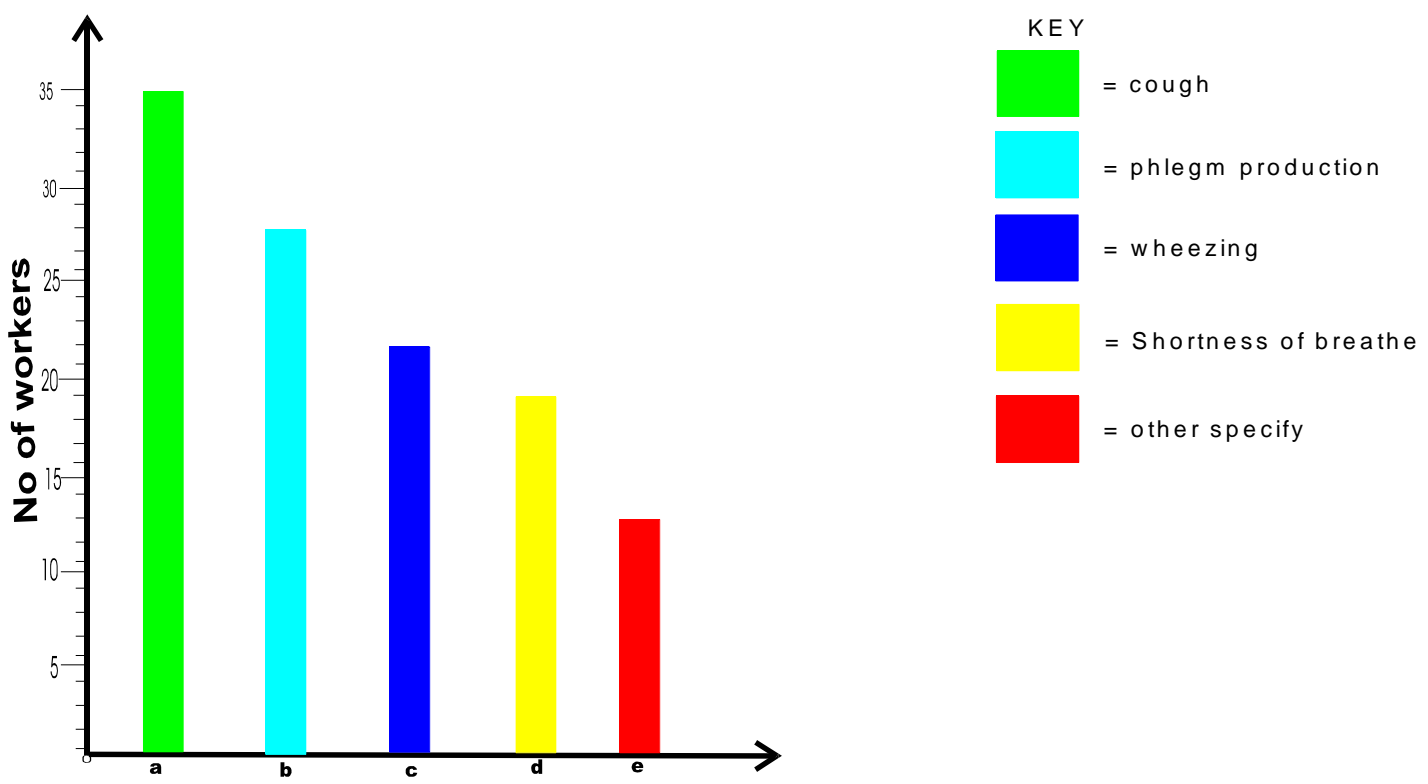

However, it is thus far from resolved which components in bioaerosols are responsible for the effects on the respiratory system, but it seems that inhalation of fungal spores, gram positive and gram negative bacteria, endotoxic from gram negative bacteria and probably beta-glucans from the fungal cell wall are likely to be implicated to be the cause of respiratory symptoms.

It was in the light of this view, this research was carried out. Though the prevalence of the respiratory infections obtained were statistically not significant $(\mathrm{P}$-value $=0.3)$ and (P> 0.05). This could be attributed to the rate of exposure of the workers, since a higher percentage of $24(45.3 \%)$ of the workers are within 1-2 years of exposure. It can also be as a result of the immunological status and certain personal occupational hygiene practices such as wearing of face masks. The immunological status of the host plays a critical role in determining the 3 reaction of host which includes saprophytic, infective and allergenic.
The study also revealed that there is a statistical significance $(\mathrm{P}<0.05)$ on the number of fungi isolated from the workers. $A$ flavus and Trichoderma viride were the lowest to be isolated with prevalence of 5 (6.3\%) each, following by Penicillium marneffei with prevalence rate of 6 (7.5), Cladosprium herbarum $8(10 \%)$ and Candida albicals8 (10\%). Aspergillus species which are ubiquitious molds found mostly in organic wastes, remained the most prevalent with Aspergillus fumigatus 9 (11.3\%) and Aspergillus niger 16 (20.0\%). Correlation between sex and age on the prevalence of respiratory fungal infections was found to be statistical insignificant with sex $(\mathrm{T}=0.268)$ and age $(\mathrm{P}=0.852)$ and hence $(\mathrm{P}>0.05)$. This shows in essence that prevalence of respiratory fungal infection in municipal solid-waste workers does not have any form of correlation with gender and age; it then shows that it is not gender specific or age predisposition. The study equally shows that the higher the years of exposure in terms of work experience, the greater the respiratory 
symptoms and higher the number of fungal isolates. Result showed that $6(20 \%)$ workers out of 53 workers recruited in general had at least seven years of experience, 4 workers out of the 6 had three (3) different fungal isolates growing, while the remaining two workers had no growth. The other 2 that had no growth might have been under medications with antifungal agents.

On the other hand, the frequency of the isolates from workers within 1-2 years of works exposure showered that $2(8.3 \%)$ of the workers had no growth. This particular findings was strongly supported when the results on their lifestyle (work habits was analyzed.

The result showed that $8(15.1 \%)$ of the workers were smoke addicts, the effect of smoking are its impacts on the respiratory much cannot be over emphasized, 6(11.3\%) smokes sometimes, while $4(7.5 \%)$ rarely smokes, $35(66 \%)$ of the workers do not smoke at all.

Also the study revealed that $40(75.4 \%)$ of the workers do not wear mask while on duty, this could be bordered on their low level of education because of this, this group are in a great risk of diseases associated with the job. Also workers do not wear protective clothing $37(70 \%), 40$ (75\%) nose mask all enabling the airborne pathogens. This concurred with the findings of Inyang (2008) in her study of the health and safety risks among the municipal solid-waste workers in PortHarcourt Metropolis of the Niger Delta region of Nigeria.

In the study, results on hematological finding of the solid-waste workers $(n=53)$ and nonsolid waste workers $(n=32)$, revealed that there was no statistical differences between the mean values of PCV of the subjects (MSWWs) (mean PCV $=3902$ ) and those of the control (Non-solid-waste workers (mean
$\mathrm{PCV}=.39), \mathrm{P}=0.325$ since $(\mathrm{P}>0.05)$. result is so, because the job is not associated with any form of anemia but there may exist, different changes in the morphology of the red cells, due to the effect of some chemicals and volatile organic compounds (VOCs) which they inhale.

The mean total white cell count of the subjects $(\mathrm{T} . w b c=6.992)$ were found to be significantly different from that of the control group (mean $\mathrm{T}$. wbc $=8.950$ ), with a $\mathrm{P}$-value of $0.000, \quad(\mathrm{P}<0.05)$. This significant difference is due to eosinophilia and to some extent neutrophilia in this group of workers. There may also exist, co-infection with parasites.

Neutrophil count with a mean value of (40.38) for the subjects and (43.56) for the control, was found to be statistically significant with a $\mathrm{P}$-value of 0.040 , hence $(\mathrm{P}$ $<0.05)$.

The basophil, lymphocyte and monocyte counts were found not be significant $(\mathrm{P}>$ $0.05)$.

In the study, the eosinophil count with a mean value of (5.47) for the subjects (municipal solid waste workers) and (2.73) for the control groups was found to be statistically significant $(\mathrm{P}<0.05)$.

This eosinophilia is due to the air borne fungi being implicated as aeroallergens and can cause hypersensitivity reactions, chronic obstructive pulmonary diseases allergic alveolitis, and organic dust toxic syndromes and asthma. Eosinophilia in this group can also occur. This finding is accordance with that of Heldal (2003).

Municipal solid-waste workers (MSIWWS) are exposed to a number of infections agents such as bacteria, fungi, viruses and parasites, toxic substances (endotoxins and beta 
glucans), chemicals that come from the waste itself and violate organic compounds (VOCs) arising from decompositions as well as vehicle exhaust fumes and noise. As a result of their exposure to these multiple risk factors, waste collectors suffer high rates of occupational health problems, owing to the fact that less awareness are being created on their work habits. In this study, it was observed that most allergenic fungal pathogens were present and this could predispose the workers to having allergic alveolitis, organic dust toxic syndrome (ODTS) etc. their hematological parameters showed that their eosinophil count was high (eosinophilia) and was statistically significant (0.000) $(\mathrm{P}<0.05)$, this is in part, due to the asthma, allergic reactions and also poor personal hygiene of the workers which creates room for parasitic infection.

\section{References}

Britannica Concise encyclopaedia retrieved (2007).

Cheesbrough, M., (2005). District Laboratory Practice in Tropical Countries, part 2 $2^{\text {nd }}$ edition. Cambridge University Press, New York, USA. Pg. 297-298.

Clapp, W.D., Becker, S., Quay, J., Watt, J.L., Thorne, P.S., Frees, K.L., Zhang, X., Koren, H.S., Lux, C.R. and Schwartz, D.A, (1994). Solid waste dust - induced air flow obstruction and inflammation of the lower respiratory tract., American Journal of Critical Care and Medicine Vol. 150.Pg 611-7

Cointreau-Levine, S., Listorti, J.and Furedy, C. (1998). Solid-waste; International Journal of Occupational and Environmental medicine Vol. 38: Pg. 620-632.

DeHoog, G.S., Guarro, J., Geene, J. and Figueres, M.J. (2000). Atlas of clinical gungi $2^{\text {ne }}$ edition, central bureau Voorschimmel cultures uterdit ISBN
90-70351-43-9.

Dorevitch, S., and Marder, D. (2001). Occupational hazards of municipal solid-wsate workers; Journal of Occupational and Environmental Medicine; Vol. 16: Pg. 125-33.

Douwes,J., Dubbeld, H. and van Zwieten, L. (2000). Upper airway inflammation assessed by nasal lavage in exposure, American Journal of Industrial Medicine Vol. 37: 459-69.

Egbokhare, K., Francis, O., Oyetade, S. and Oluwole, W. (2002). Harmonization and standardization of Nigerian language; CASAS Group. Pg. 106.

Environmental Protection Agency, (EPA), (2012). Municipal waste. http//www.EPAGoo//osw//nonhaz/municipal index.htm.

FederalRepublic of Nigeria Official Gazette (FRNOG), (2006). Legal notice on publication of the details of the Breakdown of the National and State Provisional Totals vol. 15 Pg. 45-7.

Hansen, J. (1997). Respiratory Symptoms among Danish waste collectors; Annals of Agricultural and Environmental Medicine Vol. 4: Pg. 69-74.

Hayes, R.B., van Nieuwenhuijsen, J.P., Raatgever, J.W.and Kate, F.J.W. (1984). Aflatoxin exposures in the industrial settings: an epidemiological study of mortality; Food Chemical Toxicology (FCT): Vol. 22. Pg. 39-43.

Heldal, K.K. (2003). Upper airway inflammation in waste handlers exposed to bioaerosols. Journal of Occupational and Environmental Medicine, Vol. 60: Pg. $440-450$.

Heldal, K.K., (2004). Association between acute symptoms and bioaerosol exposure during the collection of household waste; American Journal of Industrial Medicine Vol. 46: Pg. 253260.

Inyang, M.P. (2007). Health and Safety Risks 
amongst the municipal solid-waste collectors in Port-Harcourt Metropolis of the Niger Delta region of Nigeria; Waste Management Environmental. Geotechnology and Global sustainable Development Vol. 12. Pg. 163-165.

Lacey,.J., and Dutkiewicz,.J. (1994). Bioaerosol and occupational lung disease; Journal of Aerosol scienceElsevier Vol. 25. Pg. 1271-1404.

Lavoie, J., Dunkerley, C.J., Kosatsky, T. and Dufresne, A. (2006). Exposure to aerosolized bacteria and fungi among collectors of commercial, mixed residential, recycabler and compostable waste; Journal of Science of Total environmental, Vol370. Pg 23-28.

Matheson, M.C. (2005). Biological dust exposure in the work place is a risk factor for chronic obstructive pulmonary disease. Thorax Vol. 60. Pg. 645-651.

Minahan, J. (2002). Encyclopedia of the stateless Nations: 5-2 Greenwood publishing Group Pg. 762.

Ochei, J and Kolhatkar, A. (2000). Identification of fungal isolates; Medical Laboratory Science: Theory and Practice Medical Mycology (part four). Pg 1080 - 84.

Okanga, K., Eloka, P.N. and Uche, M. (2003). NjepuAmaka migration is rewarding: a socio culture anthropological study of global economic migration. Peter Lary. P.63. ISBN $0-8204-6090-7$

\section{How to cite this article:}

Ekejindu, I.M., C.F. Aniebue, M.T.B. Ochiabuto and Obeagu, E.I. 2017. Common Respiratory Fungal Pathogens in Municipal Solid Waste Workers in Anambra State, Nigeria. Int.J.Curr.Microbiol.App.Sci. 6(10): 421-436. doi: https://doi.org/10.20546/ijcmas.2017.610.052 